Article

\title{
Effects of a Dynamic Injection Flow Rate on Slug Generation in a Cross-Junction Square Microchannel
}

\author{
Jin-yuan Qian ${ }^{1,2,3} \mathbb{C}$, Min-rui Chen ${ }^{1}$, Zan Wu ${ }^{2}$, Zhi-jiang Jin ${ }^{1}\left(\mathbb{C}\right.$ and Bengt Sunden ${ }^{2, *} \mathbb{C}$ \\ 1 Institute of Process Equipment, Zhejiang University, Hangzhou 310027, China; qianjy@zju.edu.cn (J.-y.Q.); \\ chenminrui@zju.edu.cn (M.-r.C.); jzj@zju.edu.cn (Z.-j.J.) \\ 2 Department of Energy Sciences, Lund University, P.O. Box 118, SE-22100 Lund, Sweden; \\ Zan.wu@energy.lth.se \\ 3 State Key Laboratory of Fluid Power and Mechatronic Systems, Zhejiang University, \\ Hangzhou 310027, China \\ * Correspondence: bengt.sunden@energy.lth.se; Tel.: +86-0571-87951216
}

Received: 3 September 2019; Accepted: 16 October 2019; Published: 18 October 2019

check for updates

\begin{abstract}
The injection flow rates of two liquid phases play a decisive role in the slug generation of the liquid-liquid slug flow. However, most injection flow rates so far have been constant. In order to investigate the effects of dynamic injection flow rates on the slug generation, including the slug size, separation distance and slug generation cycle time, a transient numerical model of a cross-junction square microchannel is established. The Volume of Fluid method is adopted to simulate the interface between two phases, i.e., butanol and water. The model is validated by experiments at a constant injection flow rate. Three different types of dynamic injection flow rates are applied for butanol, which are triangle, rectangular and sine wave flow rates. The dynamic injection flow rate cycles, which are related to the constant slug generation cycle time $t_{0}$, are investigated. Results show that when the cycle of the disperse phase flow rate is larger than $t_{0}$, the slug generation changes periodically, and the period is influenced by the cycle of the disperse phase flow rate. Among the three kinds of dynamic disperse flow rate, the rectangular wave influences the slug size most significantly, while the triangle wave influences the separation distance and the slug generation time more prominently.
\end{abstract}

Keywords: liquid-liquid slug flow; slug generation; dynamic injection flow rate; microchannel; Computational Fluid Dynamics

\section{Introduction}

Due to the excellent uniform size and dynamic flow characteristics, slug flow inside microchannels has been widely used in a variety of fields [1,2]. A lot of scholars have contributed to this research topic. Many researchers pay attention to the gas-liquid two-phase slug flow in microchannels. For instance, Ryo et al. [3] conducted experiments to measure the void fraction and pressure drop of gas-liquid slug flow in circular microchannels with different diameters. They proposed a model to predict the distributions very well. Liu et al. [4] investigated the effects of capillary number and flow rate ratio on the slug-bubble flow by conducting experiments and numerical simulations. They developed a correlation to describe the relationship between bubble length, capillary number and flow rate ratio. Patel et al. [5] conducted experiments in a microchannel to observe the effects of operating conditions and the channel size on the liquid film thickness of bubbles in an air-water slug flow regime. It was found that the liquid film thickness in the corner of the square channel cross section decreased with the increase of the capillary number. Additionally, a correlation for the calculation of the film thickness was proposed with an error within an acceptable range. 
Rocha et al. [6] conducted numerical simulations to investigate the Taylor bubbles in circular milli and microchannels for a wide range of Reynolds and Capillary numbers, and the shape and velocity of isolated Taylor bubbles, as well the liquid films surrounding the bubbles, were analyzed. They found different recirculation patterns of liquid slugs and different velocity characteristics of bubbles, for low and high Capillary numbers. Meanwhile, the thickness of films surrounding the bubbles were found almost stagnant at low Capillary and Reynolds numbers, and the bubble velocity could be estimated extremely accurately by the stagnant film hypothesis, especially at low Capillary numbers. Kingston et al. [7] created a novel experimental facility to control the hydrodynamic quantification and heat transfer of the microchannel slug flow boiling transport. Svetlov et al. [8] carried out experiments with a coaxial-spherical micro mixer and optimized the nozzle positions. The dependence of the Taylor flow regime upon liquid superficial velocity was weakened, and equations used to calculate the bubbles and slugs were obtained. Yao et al. [9-11] conducted a series of experiments to investigate the gas-liquid mass transfer in the slug flow regime by an online photographic method to measure the mass transfer coefficient of $\mathrm{CO}_{2}$ bubbles. Yin et al. [12] also adopted $\mathrm{CO}_{2}$ as the gas phase, and observed slug-bubbly flow, slug flow and slug-annular flow, where the void fraction and frictional pressure drop of the slug flow regime were mainly investigated. Liu et al. [13] carried out a numerical study to investigate the transition from the slug flow to the annular flow of convective boiling with high heat flux in a microchannel, and it was found that the transition of the flow regime had a positive impact on bubble evaporation. Magnini and Thome [14,15] investigated the effects of the primary flow parameters on the boiling heat transfer performance of a slug flow by means of numerical simulation. It was concluded that the heat transfer performance was enhanced by flow conditions, making the liquid film of the bubble thinner, and they proposed a new physical model to update the three-zone model, which had been widely used for slug flow boiling in microchannels. Li et al. [16] investigated the two-phase flow of R32 in a parallel-port microchannel, where the two-phase flow was generated by heating the subcooled refrigerant, and proposed the flow pattern map of R32.

In addition, many scholars have paid attention to the research of liquid-liquid slug flow. Garstecki et al. [17] conducted a pioneering investigation on the process of the formation of droplets and bubbles in a T-junction microchannel, and threw light on the mechanism of the break-up of the dispersed phase fluid at a low capillary number. Sattari-Najafabadi et al. [18,19] conducted experiments in cross-junction rectangular microchannels to investigate the effects of the aspect ratio and the channel size on the liquid-liquid mass transfer within the slug regime. They found that a smaller square microchannel was conducive to mass transfer. Kovalev et al. [20] investigated the flow hydrodynamics of liquid-liquid flow with a low viscosity ratio in a T-junction rectangular microchannel by presenting an experimental study. They observed six flow patterns, including a specific slug flow, where micro-sized droplets were generated. Carneiro et al. [21] studied the droplet formation regimes of immiscible fluids with low viscosities, which contained surfactant, by experimental and numerical methods. The effects of surfactant mass transport limitations, and of the interface rheology, are analyzed. A numerical method, which was based upon a coupled level-set and volume of fluid method, estimated the droplet size accurately. Zhang et al. [22] carried out experiments in a T-junction microchannel to investigate the effect of the elasticity of the PEO-glycerol solution on the dynamics of droplet generation. They observed four flow regimes, and researched the stages of droplet generation in detail. Qian et al. [23] investigated the slug flow pattern in a T-junction microchannels. The effects of the flow rates of two phases and the geometry properties of microchannel on the generation of slugs were analyzed in detail. A new flow stage, called lag stage merges, was observed. Man et al. [24] used a step surface to break liquid-liquid slugs into droplets by experiments, and found a critical slug length for the breakup. Wehking et al. [25] conducted an experimental study in a T-junction microchannel to investigate viscosity, interfacial tension and flow geometry on droplet formation. They developed empirical correlations to predict the transition regions for the slug and dripping regimes. Zhang et al. [26] conducted experiments in circular microchannels with different diameters at different temperatures to investigate the hydrodynamics and mass transfer characteristics of liquid-liquid slug 
flow; results revealed the roles of inertia and viscous force in the transition of liquid-liquid flow patterns, as well as the effects of temperature on mass transfer.

Song et al. [27] investigated the hydrodynamics and mass transfer performance of a liquid-liquid slug flow regime in a microreactor, where the chemical oxidative polymerization of aniline was happening. They found that the internal recirculation in dispersed phase slugs was beneficial for the mass transfer in the polymerization, and obtained a combination of residence time and temperature, with which a high level polyaniline yield was reached. Qian et al. [28] investigated the mixing efffeciency on droplet formation process in microchannels with three shapes, aided by the CFD method. The mixing performance in different microchannels were compared, and found that the cross-shaped T-junction was the best. Van Loo et al. [29] studied the droplet formation in a cross-junction microchannel by experimental methods. They mainly focused on two steps of slug generation, and several scaling laws were proposed to relate the droplet volume and generation frequency. Zhao et al. [30] investigated the behavior of slug flow to prepare cryogel beads in a rectangular microchannel, and correlations of the liquid-liquid slug flow parameters were obtained for the bead diameter estimation. Malekzadeh et al. [31] utilized the OpenFOAM code to simulate the droplet formation in a T-junction microchannel, and found that when the contact angle increased, the droplet detachment time increased in the slug flow regime, while it decreased in the dripping regime. Gupta et al. [32] analyzed the effects of viscoelasticity on the liquid threads breakup in a cross-junction microchannel, by mesoscale lattice Boltzmann methods. It was found that the break-up point of the liquid thread was affected more pronouncedly with matrix viscoelasticity. Chen et al. [33] proposed a 3D physical model to describe the slug generation process in a cross-junction microchannel. Li et al. [34] studied the mechanism of liquid-liquid droplet formation in a T-junction microchannel numerically and analytically. They found that the surface force and viscous force played significant roles in the droplet regime. Ładosz et al. [35] proposed two models to calculate the pressure drop of liquid-liquid slug flow in square microchannels, and found that the models were reliable in predicting the pressure drop of liquids with similar viscosities. Qian et al. [36] conducted numerical investigation in serpentine microchannels to analyze the effects of bend radius of the microchannels on the mixing efficiency in liquid-liquid two-phase flow, the pressure drop in the microchannel was researched as well.

Our research group has also paid attention to the microchannel topic, Qian et al. [37] conducted numerical simulations on the nanofluids flowing through a micro Tesla valve. Based on the investigations mentioned above, the fluid injection flow rate is commonly constant. However, a dynamic injection flow rate may precisely control the slug size and the distance between two neighboring slugs. For instance, when a fixed slug size is required, and the continuous phase is expensive, the dynamic injection flow rate can control the slug size and the separation distance between slugs to reduce the cost. In this paper, firstly slugs generated in a cross-junction microchannel at constant flow rates are studied experimentally and numerically. The experimental and numerical data are compared to validate the reliability of the numerical method. Then, as the experimental conditions are limited, the numerical simulations of slug generation are extended to handle the condition of dynamic dispersed phase injection flow rates. The slug size, the separation distance and the generation time are analyzed to discover the effects of the dynamic dispersed phase injection flow rate on the slug generation process.

\section{Experimental Setup}

Figure 1 presents the experimental setup. It was built up by syringe pumps (New Era, NE-4000, New Era Pump Systems, 138 Toledo St, Farmingdale, NY 11735, US), a cross-junction microchannel chip, a microscope (Motic, SMZ-171, Motic Microscopes, Roanoke, VA, US), a digital camera (Olympus OM-DE-M1, Olympus Cameras, Shinjuku, Tokyo, Japan), and a laser light source. In this setup, the microchannel chip was fabricated by borosilicate glass. A cross-junction microchannel had been carved onto the chip, and the thermal bonding technique, which had excellent chemical resistance, 
was adopted to seal the channel. The microchannel geometrical parameters are shown in Figure 2 . The cross section of the microchannel was a square, and the channel width $W$ was $0.6 \mathrm{~mm}$. To avoid the entrance effect, the length of the entrance sections was $10 \mathrm{~W}$. In addition, the length of the section downstream from the cross-junction was $50 \mathrm{~W}$, so that the slug flowing pattern could be fully developed. The continuous phase (water) was injected from the two side channels, and the dispersed phase (butanol) was injected from the central channel. The slug size was represented by its maximum length $d$, and the separation distance was represented by its minimum length $l$, as shown in Figure 2 .

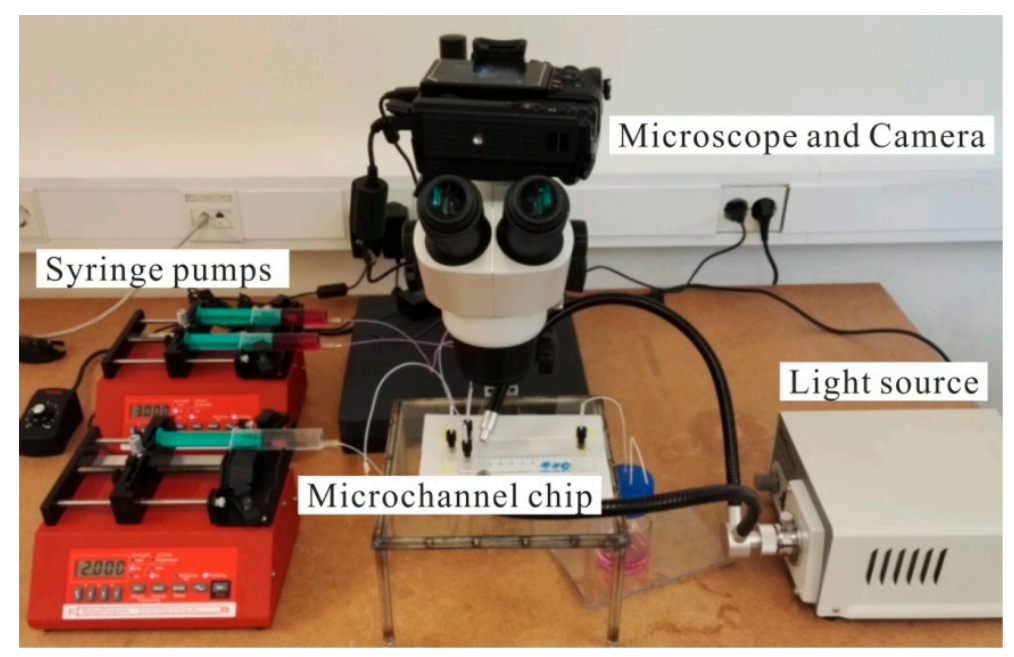

Figure 1. Experimental setup.

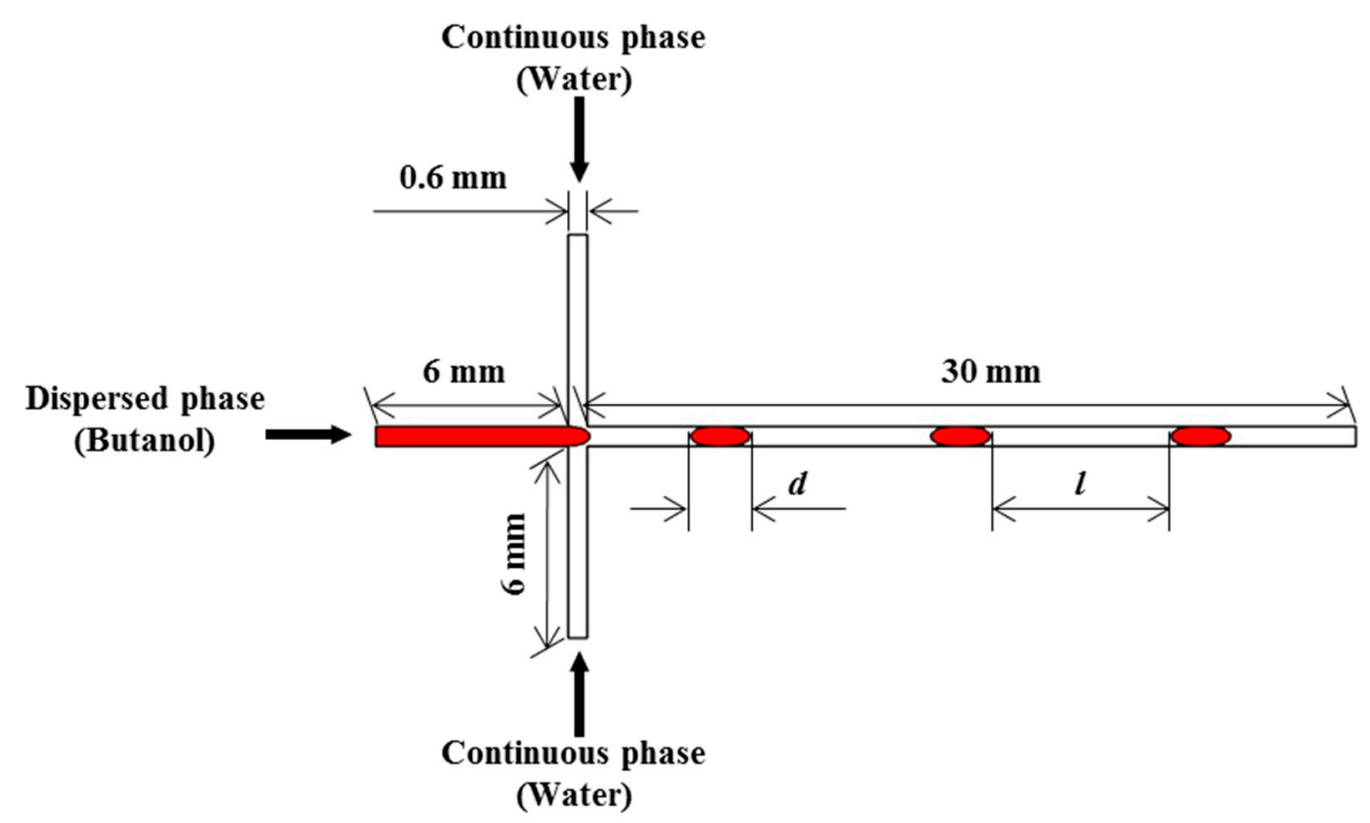

Figure 2. Geometry parameters of the microchannel.

In this experiment, syringe pumps were used to control the injection flow rate, which was kept constant, similar to the common situations. The slugs inside the microchannel were observed by a microscope, and the images were captured by a digital camera. A laser light source was employed to provide sufficient lightness for the image shoot. Finally, a bottle was connected to the outlet of the microchannel to collect waste liquids.

During the experiment, the water phase was firstly introduced into the microchannel for several minutes before injecting the butanol phase in order to get stable slugs. The slug length and slug velocity 
were extracted and averaged from 10 snapshots and videos. The experimental setup had been used in previous studies, and the experimental uncertainty is within $\pm 5 \%$, as mentioned in reference [38].

\section{Numerical Method}

\subsection{Mathematical Model}

The CFD simulation of flow in a micro device has been studied by many researchers, especially for the discussion on the liquid film capture [39]. It should be said that Volume of Fluid (VOF) model is suitable and can be adopted in this investigation. In this model, the volume fraction of the continuous phase $\alpha$, which ranges from 0 to 1 , is used to judge whether the control volume contains the interface of the two phases or not. If $\alpha$ is equal to 0 , the control volume is full of the dispersed phase. If $\alpha$ is equal to 1 , the control volume is full of the continuous phase. If $\alpha$ is larger than 0 but less than 1 , the control volume is mixed by the two phases, and contains the interface between the two phases. In a control volume, the physical properties of the fluid, such as density and viscosity, are calculated by the volume fractions of the two phases.

When the VOF model is adopted, the tracking of the interface(s) between the phases is accomplished by the solution of a continuity equation for the volume fraction of one (or more) of the phases. In the present investigation, there are two phases. Taking the continuous phase as an example, this equation can be expressed as the following form:

$$
\frac{1}{\rho_{c}}\left[\frac{\partial}{\partial t}\left(\alpha_{c} \rho_{c}\right)+\nabla \cdot\left(\alpha_{c} \rho_{c} \vec{v}_{c}\right)\right]=\frac{1}{\rho_{c}} \sum_{p=1}^{n}\left(\dot{m}_{d c}-\dot{m}_{c d}\right)
$$

where, $\rho$ is the density, $\alpha$ is the fraction of continuous phase, the subscripts $c$ and $d$ represent the continuous and disperse phase, respectively. The symbol $\dot{m}_{d c}$ is the mass transfer from the dispersed phase to the continuous phase, and the symbol $\dot{m}_{c d}$ is the mass transfer from the continuous phase to the dispersed phase.

In the VOF model, a single momentum equation is solved throughout the domain, and the resulting velocity field is shared among the phases. The momentum equation, expressed as Equation (2), is dependent upon the volume fractions of all phases through the properties $\rho$ and $\mu$.

$$
\frac{\partial}{\partial t}(\rho \vec{v})+\nabla \cdot(\rho \vec{v} \vec{v})=-\nabla p+\nabla \cdot\left[\mu\left(\nabla \vec{v}+\nabla \vec{v}^{T}\right)\right]+\rho \vec{g}+\vec{F}
$$

where, $\mu$ is the viscosity. For the continuous and dispersed phases in this study, the properties $\rho$ and $\mu$ are calculated by following equations:

$$
\begin{aligned}
& \rho=\rho_{c} \alpha+\rho_{d}(1-\alpha) \\
& \mu=\mu_{c} \alpha+\mu_{d}(1-\alpha)
\end{aligned}
$$

Taking the continuous phase as an example, the source term is written as follows:

$$
F=2 \gamma \frac{\rho \kappa_{c} \nabla \alpha}{\rho_{c}+\rho_{d}}
$$

where, $\gamma$ represents the surface tension between the two phases, and $\kappa_{c}$ is the curvature of the interface which is determined as follows:

$$
\kappa_{c}=\nabla \cdot \hat{n}
$$

For the control volumes far away from the wall and the cells close to the wall, the unit normal vectors are derived from Equation (5) and (6), respectively: 


$$
\begin{gathered}
\hat{n}=\frac{n}{|n|}, n=\nabla \cdot \alpha \\
\hat{n}=\hat{n}_{c} \cos \theta+\hat{t}_{c} \sin \theta
\end{gathered}
$$

where, $\theta$ is the contact angle, $\hat{n}_{c}$ and $\hat{t}_{c}$ represent the normal and tangential vectors, respectively.

\subsection{Mesh and Boundary Conditions}

A 3D physical model of the cross-junction microchannel corresponding to the experimental setup is established. A hexahedral mesh is used to discretize the flow channel and a mesh independence check is conducted. Aided by the software Fluent 17.2, the numerical simulations are conducted. With constant continuous and disperse phase flow rate of $0.001 \mathrm{~m} / \mathrm{s}$, the slug size is 1,183 $\mu \mathrm{m}$ when the mesh size is $40 \mu \mathrm{m}$, and the slug size is $1,172 \mu \mathrm{m}$ when the mesh size is $35 \mu \mathrm{m}$. The relative difference is within $0.95 \%$. Therefore, meshes with size of $40 \mu \mathrm{m}$ will provide numerical results with satisfactory accuracy, and the corresponding number of control volumes is 271,800 .

Consistent with the experiments, water is set as the continuous phase and butanol is set as the dispersed phase. The fluid physical properties are listed in Table 1. At room temperature, about $7.7 \mathrm{~g}$ of butanol can be dissolved per $100 \mathrm{~g}$ of water, which indicates that butanol is slightly soluble in water. The images obtained from the experiments, in which the interfaces of water and butanol were clear, proved that the slight solubility affected little on the generation of slugs. The boundary conditions are set as follows: The three inlets are set as velocity inlets. With the advantage of the user defined functions (UDFs), the dispersed phase injection flow rate can be set as a dynamic flow rate by a specified function. The outlet is set as an outflow. Then, for all other surfaces, the wall condition is adopted. The wettability of a liquid is determined by the liquid and solid properties. The contact angle of butanol is set as $150^{\circ}$. The Pressure-Implicit with Splitting of Operators (PISO) scheme is adopted to couple the pressure and velocity. Concerning the spatial discretization, the Green-Gauss Cell-Based algorithm is used for gradients, the PRESTO! algorithm is used for pressure, a second order upwind scheme is adopted for momentum, and the Geo-Reconstruct is employed for the volume fraction.

Table 1. Physical properties of two fluids.

\begin{tabular}{cccc}
\hline Fluid & Density $\left(\mathbf{k g} \cdot \mathbf{m}^{-\mathbf{3}}\right)$ & Viscosity (mPa.s) & Surface Tension (N.m $^{\mathbf{- 1}}$ ) \\
\hline Water & 998.2 & 1.003 & 0.0018 \\
Butanol & 810 & 2.95 & \\
\hline
\end{tabular}

\section{Results and Discussion}

\subsection{Numerical Method Validation}

The flowing pattern obtained from the numerical simulation is compared with the experimental data for the validation purpose. These experiments and simulations were conducted for the condition of a constant injection flow rate.

\subsubsection{Experimental Results}

In the experiments, the constant injection flow rates both for the continuous and dispersed phase were set as $0.001 \mathrm{~m} / \mathrm{s}, 0.002 \mathrm{~m} / \mathrm{s}, 0.003 \mathrm{~m} / \mathrm{s}$ and $0.004 \mathrm{~m} / \mathrm{s}$, respectively. The images captured by the digital camera were used to measure the slug size and separation distance. According to the characteristics of similar figures, the ratio between the channel width $(600 \mu \mathrm{m})$ and the real slug size equals the ratio between the values measured from the pictures. As shown in Figure $3, x$ represents the measured slug maximum length, and $y$ represents the measured channel width. 


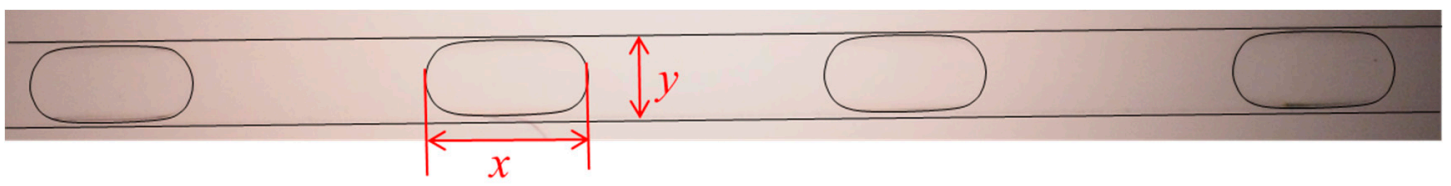

Figure 3. Schematic diagram of measurement mode.

Thus the slug size $d$ can be calculated by the Equation $d=600 \times \frac{x}{y}$. With the same method, the separation distance was measured.

In order to make the slug size and separation distance more accurate, 10 values were measured for each operating condition. The measured slug sizes are listed in Table 2, and the measured separation distances are listed in Table 3. These data show that the slugs were generated uniformly for the constant injection flow rates. Comparing every measured slug size and separated distance with their average values, the maximum related differences are less than $\pm 0.5 \%$, which indicates that the measurements of slug size and separation distance are stable, and that the slug size and separation distance can be represented by their average values.

Table 2. The slug size of experiments.

\begin{tabular}{|c|c|c|c|c|c|c|c|c|}
\hline \multirow{3}{*}{$\begin{array}{c}u_{c}(\mathrm{~m} / \mathrm{s}) \\
0.001\end{array}$} & \multirow{3}{*}{$\begin{array}{c}\begin{array}{c}u_{d} \\
(\mathrm{~m} / \mathrm{s})\end{array} \\
0.001\end{array}$} & \multicolumn{5}{|c|}{ Sizes of 10 Slugs $(\mu \mathrm{m})$} & \multirow{3}{*}{$\begin{array}{c}\begin{array}{c}\text { Average Slug } \\
\text { Size }(\mu \mathrm{m})\end{array} \\
1183\end{array}$} & \multirow{3}{*}{$\begin{array}{c}\text { The Maximum Related } \\
\text { Difference (\%) } \\
0.42\end{array}$} \\
\hline & & 1182 & 1185 & 1188 & 1180 & 1183 & & \\
\hline & & 1186 & 1183 & 1183 & 1181 & 1182 & & \\
\hline \multirow{2}{*}{0.002} & \multirow{2}{*}{0.002} & 1065 & 1069 & 1068 & 1064 & 1067 & \multirow{2}{*}{1066} & \multirow{2}{*}{-0.38} \\
\hline & & 1062 & 1066 & 1065 & 1067 & 1066 & & \\
\hline \multirow{2}{*}{0.003} & \multirow{2}{*}{0.003} & 1029 & 1026 & 1024 & 1027 & 1026 & \multirow{2}{*}{1026} & \multirow{2}{*}{0.39} \\
\hline & & 1030 & 1025 & 1026 & 1028 & 1024 & & \\
\hline \multirow{2}{*}{0.004} & \multirow{2}{*}{0.004} & 928 & 926 & 923 & 924 & 926 & \multirow{2}{*}{926} & \multirow{2}{*}{0.32} \\
\hline & & 926 & 925 & 929 & 926 & 927 & & \\
\hline
\end{tabular}

Table 3. The separation distance of experiments.

\begin{tabular}{|c|c|c|c|c|c|c|c|c|}
\hline \multirow{3}{*}{$\begin{array}{c}u_{c}(\mathrm{~m} / \mathrm{s}) \\
0.001\end{array}$} & \multirow{3}{*}{$\begin{array}{c}\begin{array}{c}u_{d} \\
(\mathrm{~m} / \mathrm{s})\end{array} \\
0.001\end{array}$} & \multicolumn{5}{|c|}{$\begin{array}{c}\text { Lengths of } 10 \text { Separation } \\
\text { Distances }(\mu \mathrm{m})\end{array}$} & \multirow{3}{*}{$\begin{array}{c}\begin{array}{c}\text { Average } \\
\text { Separation } \\
\text { Distance }(\mu \mathrm{m})\end{array} \\
1950\end{array}$} & \multirow{3}{*}{$\begin{array}{c}\text { The Maximum Related } \\
\text { Difference (\%) }\end{array}$} \\
\hline & & 1951 & 1950 & 1948 & 1953 & 1948 & & \\
\hline & & 1952 & 1950 & 1949 & 1950 & 1947 & & \\
\hline \multirow{2}{*}{0.002} & \multirow{2}{*}{0.002} & 1518 & 1516 & 1519 & 1520 & 1515 & \multirow{2}{*}{1518} & \multirow{2}{*}{-0.19} \\
\hline & & 1520 & 1518 & 1517 & 1516 & 1519 & & \\
\hline \multirow{2}{*}{0.003} & \multirow{2}{*}{0.003} & 1274 & 1278 & 1280 & 1279 & 1274 & \multirow{2}{*}{1278} & \multirow{2}{*}{-0.31} \\
\hline & & 1278 & 1279 & 1281 & 1278 & 1276 & & \\
\hline \multirow{2}{*}{0.004} & \multirow{2}{*}{0.004} & 1299 & 1302 & 1295 & 1300 & 1299 & \multirow{2}{*}{1299} & \multirow{2}{*}{-0.31} \\
\hline & & 1298 & 1300 & 1299 & 1299 & 1301 & & \\
\hline
\end{tabular}

\subsubsection{Validation of Numerical Method}

Numerical simulations for the operating conditions of constant injection flow rates were conducted. The injection flow rates corresponded to the experiments. The flow patterns obtained from the numerical simulations were compared with the experiments. As shown in Figure 4, the simulated flow patterns agree well with the experiments. In Figure 4 , the symbols $u_{c}$ and $u_{d}$ represent the continuous and disperse phase flow rate, respectively. 


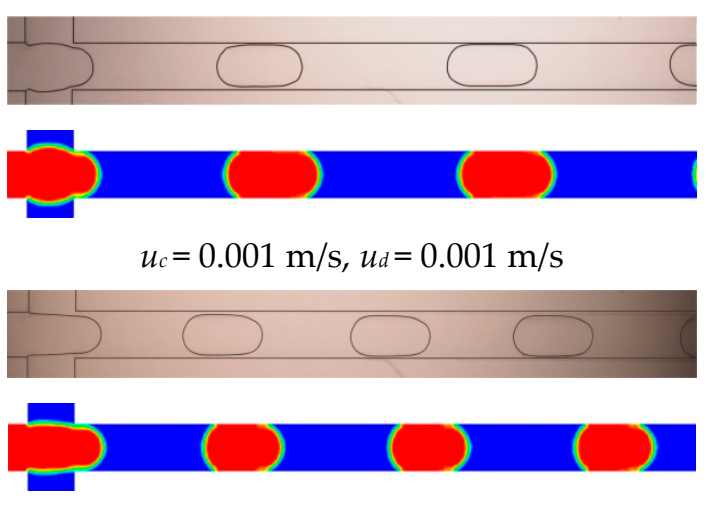

$$
u_{c}=0.003 \mathrm{~m} / \mathrm{s}, v_{d}=0.003 \mathrm{~m} / \mathrm{s}
$$

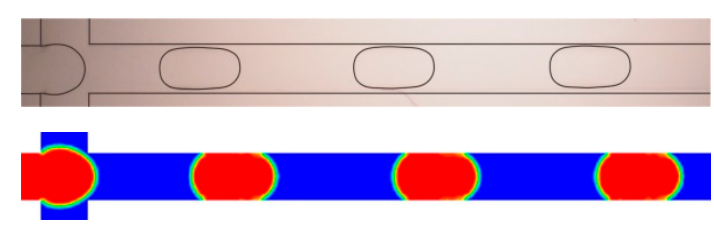

$u_{c}=0.002 \mathrm{~m} / \mathrm{s}, u_{d}=0.002 \mathrm{~m} / \mathrm{s}$

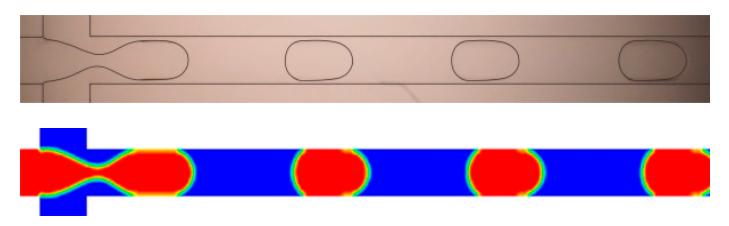

$u_{c}=0.004 \mathrm{~m} / \mathrm{s}, v_{d}=0.004 \mathrm{~m} / \mathrm{s}$

Figure 4. Flowing pattern comparison of experimental results (up) and simulated results (down).

The simulated slug size, which is the maximum slug length on the symmetry plane of the microchannel, and the simulated separation distance, which is its minimum length on the symmetry plane of the microchannel, are both compared with the experimental data. The results are shown in Table 4 . The relative errors are within $\pm 8 \%$. In fact, there are errors in both experiments and numerical simulations. Affected by the accuracy of the instruments, the injection flow rates are not always kept fixed, which will make the slug size change in the experiments. On the other hand, the pictures obtained from the experiments and the phase fraction contours obtained from the simulations are evaluated by image processing software, in which errors in the determination of the droplet boundary may occur. Accordingly, the maximum relative error, which is less than $8 \%$, is deemed acceptable. The satisfactory comparison between the simulations and the experiments indicates that the numerical method is reliable.

Table 4. Slug size comparison between experimental and simulated results.

\begin{tabular}{cccccccc}
\hline \multicolumn{2}{c}{ Injection Flow Rate } & \multicolumn{3}{c}{ Slug Length $(d / \mu \mathrm{m})$} & \multicolumn{3}{c}{ Separation Distance $(l / \mu \mathrm{m})$} \\
\hline $\boldsymbol{u}_{\boldsymbol{c}}(\mathrm{m} / \mathbf{s})$ & $\boldsymbol{u}_{\boldsymbol{d}}(\mathrm{m} / \mathrm{s})$ & Experiment & $\begin{array}{c}\text { Numerical } \\
\text { Simulation }\end{array}$ & $\begin{array}{c}\text { Relative } \\
\text { Error }(\%)\end{array}$ & Experiment & $\begin{array}{c}\text { Numerical } \\
\text { Simulation }\end{array}$ & $\begin{array}{c}\text { Relative } \\
\text { Error }(\%)\end{array}$ \\
\hline 0.001 & 0.001 & 1183 & 1236.01 & 4.5 & 1950 & 1812.05 & -7.1 \\
0.002 & 0.002 & 1066 & 1104.23 & 3.6 & 1518 & 1533.74 & 1.0 \\
0.003 & 0.003 & 1026 & 986.18 & -3.9 & 1278 & 1288.89 & 0.9 \\
0.004 & 0.004 & 926 & 934.19 & 0.9 & 1299 & 1243.61 & -4.3 \\
\hline
\end{tabular}

\subsection{Numerical Simulation Results of Dynamic Dispersed Injection Flow Rate}

In this section, the slug generation with a constant injection flow rate is numerically simulated at first. Then, the slug generation with a dynamic dispersed phase injection flow rate is analyzed. The dispersed phase dynamic injection flow rate follows three common wave types, namely, a triangle wave dynamic injection flow rate $u_{d t}$, a rectangular wave dynamic injection flow rate $u_{d r}$ and a sine wave dynamic injection flow rate $u_{d s}$, as depicted in Figure 5. The effects of the dynamic dispersed phase injection flow rate for different types and different cycles on the slug generation are also discussed.

\subsubsection{Comparison of Constant and Dynamic Injection Flow Rates}

In this section, the slug generation process under conditions of constant as well as dynamic injection flow rates is investigated.

Firstly, numerical simulations for a constant injection flow rate are conducted. The continuous phase injection flow rate at the central inlet $u_{c}$ is $0.001 \mathrm{~m} / \mathrm{s}$, and the dispersed phase injection flow rate at the side inlets $u_{d}$ is $0.001 \mathrm{~m} / \mathrm{s}$, corresponding to the experiment as shown in the first line of Table 2 . It is found that the slugs are generated uniformly. The slug generation characteristics, including the slug size, the separation distance and the generation time, are almost kept constant, i.e., independent 
of time. According to Table 2, the slug size $d_{0}$ is $1,236 \mu \mathrm{m}$, the separation distance $l_{0}$ is $1,812 \mu \mathrm{m}$. In addition, the slug generation time $t_{0}$ is $1.002 \mathrm{~s}$.

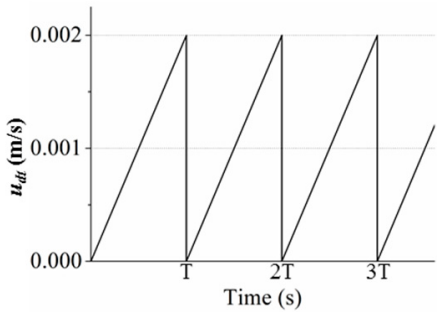

(a)

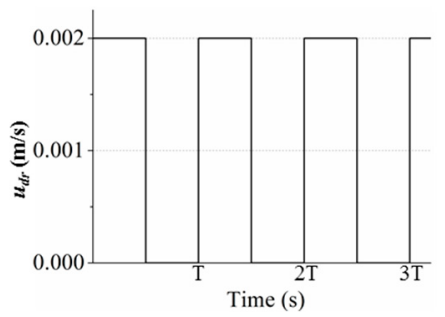

(b)

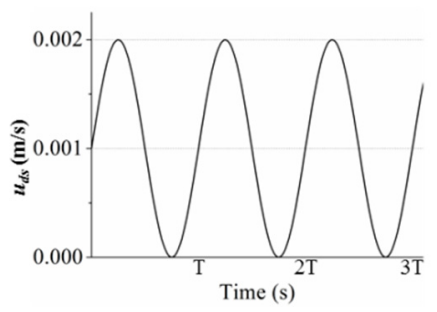

(c)

Figure 5. Dynamic dispersed injection flow rate of different types. (a) Triangle wave dynamic injection flow rate $\left(u_{d t}\right)$; (b) Rectangular wave dynamic injection flow rate $\left(u_{d r}\right)$; (c) Sine wave dynamic injection flow rate $\left(u_{d s}\right)$.

Then, the slug generation under the condition of the triangle wave dynamic dispersed phase injection flow rate is numerically simulated. The cycles of the dynamic dispersed phase injection flow rate, which are related to the slug generation time $t_{0}$, are set as $0.5 t_{0}, t_{0}$ and $2 t_{0}$, respectively. Figure 6 presents the slug flow patterns for the triangle wave dynamic dispersed phase injection flow rate with different cycles. When the cycles of the triangle wave dynamic dispersed injection flow rate are $0.5 t_{0}$ and $t_{0}$, the slugs are generated uniformly. The slug sizes are $1,235.36 \mu \mathrm{m}$ and 1,235.16 $\mu \mathrm{m}$, and the separation distances are $1,811.88 \mu \mathrm{m}$ and $1,810.45 \mu \mathrm{m}$, respectively. Compared with the values obtained from a constant injection flow rate, the relative differences of slug sizes and separation distances are both within $\pm 0.1 \%$, which reveals that the triangle wave dynamic dispersed phase injection flow rate with cycles of $0.5 t_{0}$ and $t_{0}$ has a marginal effect on the slug generation. When the cycle of triangle wave dynamic dispersed phase injection flow rate is $2 t_{0}$, however, the slug generation is not uniform anymore. The slug size and the separation distance change periodically.

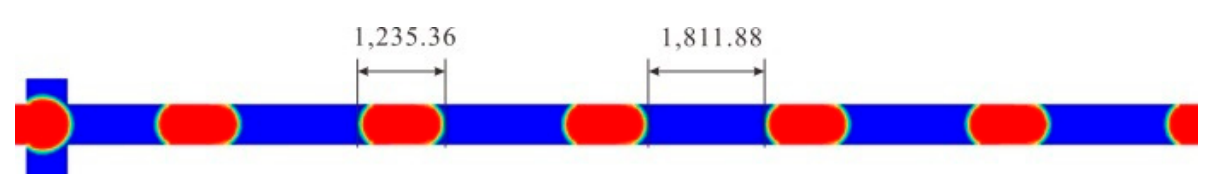

(a)

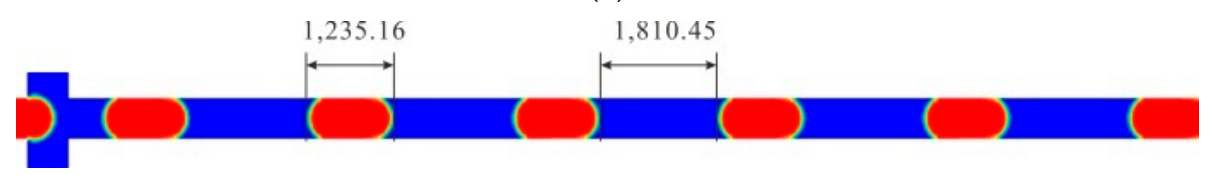

(b)

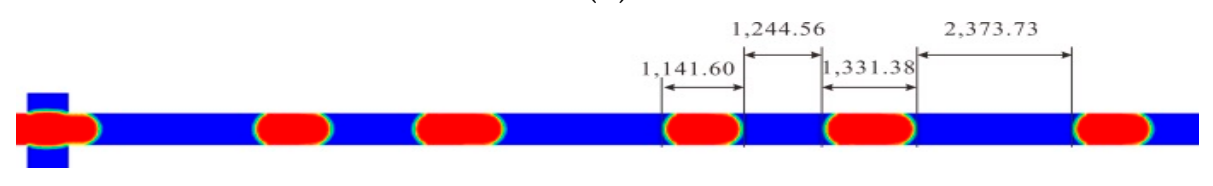

(c)

Figure 6. Flow types obtained from numerical simulations for triangle wave dynamic dispersed phase injection flow rate $(\mu \mathrm{m})$. (a) The flow type for the condition of triangle wave dynamic dispersed phase injection flow rate with a cycle of $0.5 t_{0} ;(\mathbf{b})$ The flow type for the condition of triangle wave dynamic dispersed phase injection flow rate with a cycle of $t_{0} ;(\mathbf{c})$ The flow type for the condition of triangle wave dynamic dispersed phase injection flow rate with a cycle of $2 t_{0}$. 
The times spent in generating each of the slugs are depicted in Figure 7, to further investigate the effects of the dynamic dispersed phase injection flow rate on the slug generation. When the cycles of the dynamic dispersed phase injection flow rate are $0.5 t_{0}$ and $t_{0}$, the slug generation time is equal to $t_{0}$, after the flow has become stable. However, the slug generation time changes periodically, when the cycle of the dynamic dispersed phase injection flow rate is $2 t_{0}$.

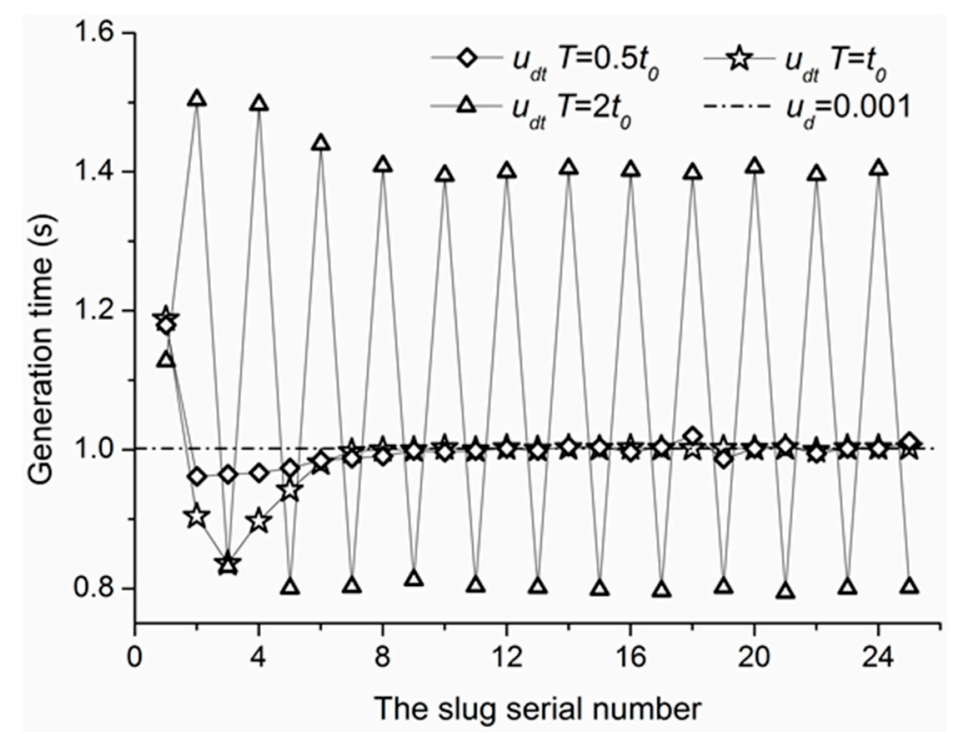

Figure 7. Slug generation time obtained from numerical simulations for a triangle wave dynamic dispersed phase injection flow rate.

The slug generation process includes three parts. At first, the dispersed phase fills the intersection of the microchannel. Then the dispersed phase stretches in the confluence channel, and at the same time, it is necked by the force from the continuous phase, which is blocked by the dispersed phase. There is a pressure drop between the intersection of the microchannel and the front end of the dispersed phase. When the pressure drop, which is affected by the continuous and dispersed phases, is larger than the tension of the two phases, the dispersed phase is broken, and a slug is generated. With a constant injection flow rate, the dispersed phase stretches in the confluent channel to a certain length, and combined with the force of the continuous phase, the critical pressure drop is achieved, at which a slug is generated, so the slug size is constant. When the cycles of the dynamic dispersed phase flow rate are $0.5 t_{0}$ and $t_{0}$, the length of dispersed phase stretching in the confluence channel equals the constant injection flow rate in the period time of $t_{0}$. By combining the continuous and dispersed phases, the slug is generated at the critical pressure drop, so the slug size equals the constant dispersed injection flow rate. When the cycle of the dynamic dispersed phase flow rate is $2 t_{0}$, the dispersed phase stretching in the confluence channel is not equal to the constant injection flow rate. A new combination of continuous and dispersed phases results in the critical pressure drop. When the dispersed phase is broken, the length over which it is stretching in the confluence channel is different from the case of the constant injection flow rate, so the slug flow type will change.

In summary, the dynamic dispersed phase injection flow rate can influence the slug generation, especially when the cycle is larger than $t_{0}$. In the following sections, the effects of the cycle and wave type on the slug generation are discussed.

\subsubsection{Cycle of the Dynamic Injection Flow Rate}

In this section, the effects of the triangle wave dynamic dispersed phase injection flow rates with different cycles on the slug generation are investigated. According to the above description, when the cycle is larger than $t_{0}$, the dynamic dispersed phase injection flow rate will affect the slug generation obviously. Here the cycles of the dynamic dispersed phase injection flow rate are set as $2 t_{0}, 3 t_{0}$ and $4 t_{0}$. 
With different cycles of the dynamic dispersed phase injection flow rate, the flow pattern, the slug size, the separation distance and the slug generation time, are analyzed. Figure 8 reveals that the slug generation changes periodically, when the cycles are $2 t_{0}, 3 t_{0}$ and $4 t_{0}$. The slug size, the separation distance and the slug generation time oscillate near the values obtained under the condition of a constant injection flow rate. When the cycle of the dynamic dispersed phase injection flow rate is $2 t_{0}$, there are two points in one slug generation cycle. When the cycle of the dynamic dispersed phase injection flow rate is $3 t_{0}$, there are three points in one slug generation cycle. Similarly, when the cycle of the dynamic dispersed phase injection flow rate is $4 t_{0}$, there are four points in one slug generation cycle. Under the conditions of a dynamic dispersed phase injection flow rate with the three cycles investigated in this section, the slug generation is periodical, and the number of slugs generated in one generation cycle is related to the flow rate cycle. As mentioned in Section 4.1, the critical pressure drop, resulting from the combination of the continuous and dispersed phases, causes the slug generation. The number of points in one cycle of the slug generation reflects how many times the critical pressure drop is achieved.

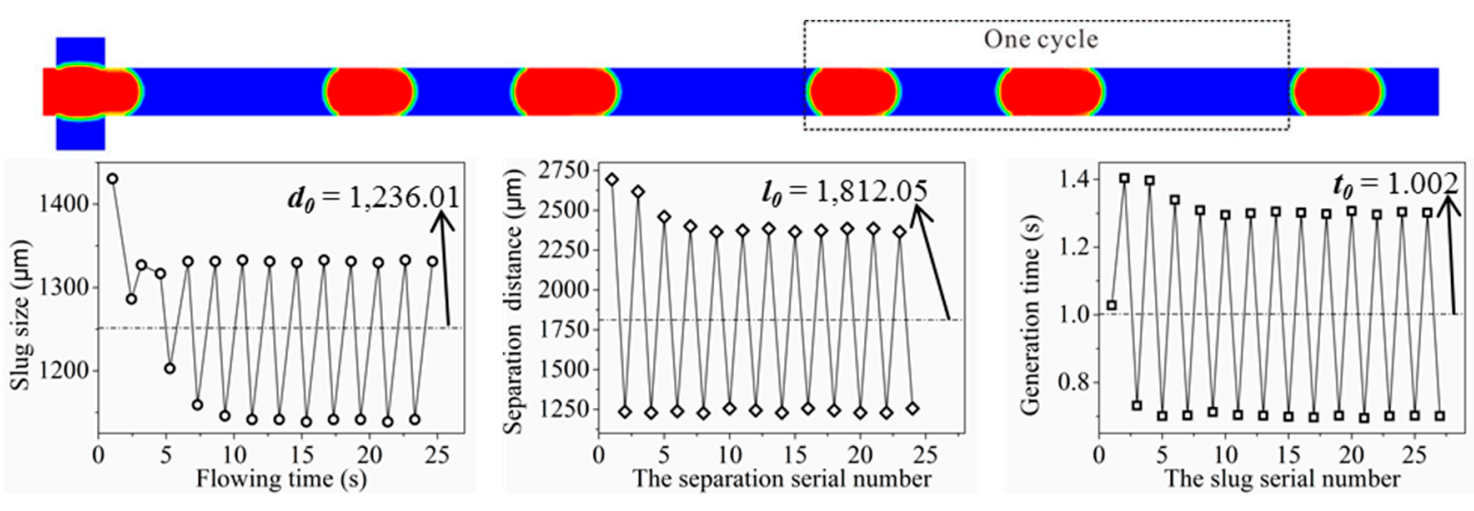

(a)
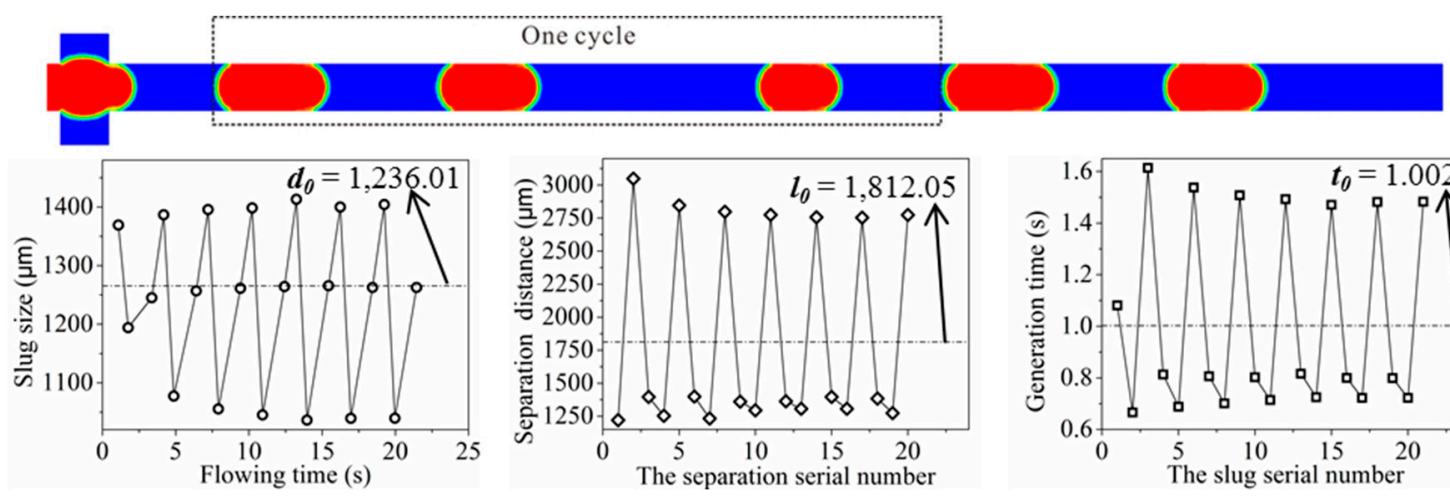

(b)

Figure 8. Cont. 


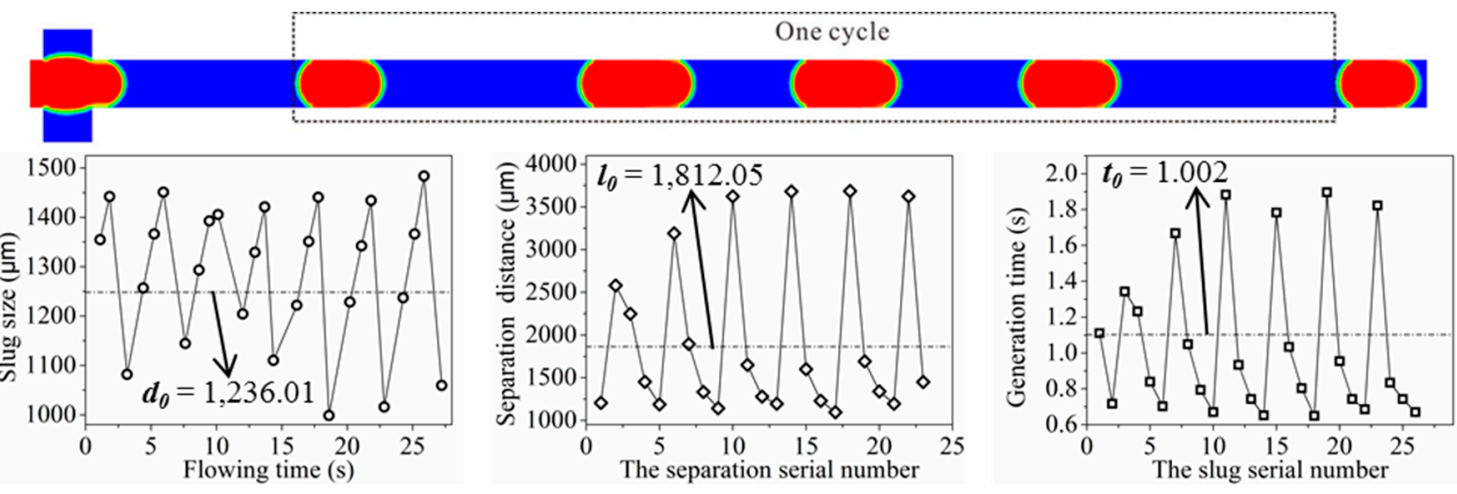

(c)

Figure 8. Slug generation obtained from numerical simulations for a triangle wave dynamic dispersed injection flow rate. (a) The slug generation for the condition of a triangle wave dynamic dispersed injection flow rate with a cycle of $2 t_{0}$; (b) The slug generation for the condition of a triangle wave dynamic dispersed injection flow rate with a cycle of $3 t_{0}$; (c) The slug generation for the condition of a triangle wave dynamic dispersed injection flow rate with a cycle of $4 t_{0}$.

The case with a dynamic dispersed phase injection flow rate cycle $3 t_{0}$ is taken as an example for further investigation. As mentioned above, there are three points in one slug generation cycle, when the cycle of the dispersed phase injection flow rate is $3 t_{0}$. Within one slug generation cycle, the sum of the slug sizes is about $3,708 \mu \mathrm{m}$, the sum of separation distances is about 5,436 $\mu \mathrm{m}$, and the sum of the generation times is about $3.006 \mathrm{~s}$. These values are about three times those under the condition of a constant injection flow rate $0.001 \mathrm{~m} / \mathrm{s}$. As shown in Figure 9, the dynamic triangle wave injection flow rate meets the following characteristic:

$$
\int_{t}^{t+T} u_{d t} d t=\int_{t}^{t+T} 0.001 d t
$$

where, $t$ is any instant of time, and $T$ is the cycle of the dynamic injection flow rate. Equation (7) reveals that for the cycles investigated, the amounts of dispersed phase flow into the microchannel are equal, when the flow time is as long as a flow rate cycle, no matter that the dispersed phase injection flow rate is constant or dynamic. Thus when the cycle of the dynamic injection flow rate is $3 t_{0}$, the sums of slug generation characteristics, including the slug size, the separation distance, and the slug generation time, are three times the values obtained under the condition of a constant injection flow rate.

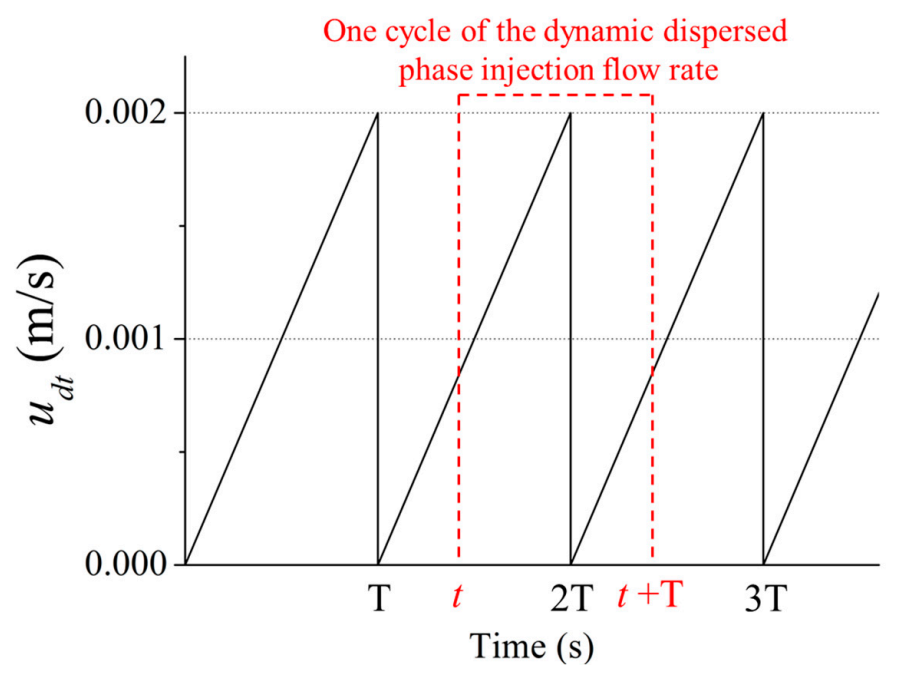

Figure 9. Integration of a triangle wave dynamic phase injection flow rate during one cycle. 


\subsubsection{Different Types of the Dynamic Injection Flow Rate}

The type of the dynamic dispersed phase injection flow rate also plays an important role on the slug generation. With the same cycle of $2 t_{0}$, the effects of the dynamic dispersed injection flow rate type, including a triangle wave, a rectangular wave and a sine wave, are studied. Figure 10 shows the slug size under the condition of dynamic dispersed phase injection flow rates of different types. The slug size changes periodically for the three kinds of dynamic dispersed phase injection flow rates, and it oscillates near $1236.01 \mu \mathrm{m}$, which is the slug size of the constant injection flow rate. In terms of the slug size amplitude, the triangle wave dynamic dispersed phase injection flow rate has the minimum amplitude, which is about $93 \mu \mathrm{m}$, while the rectangular wave dynamic dispersed phase injection flow rate has the maximum amplitude, which is about $250 \mu \mathrm{m}$.

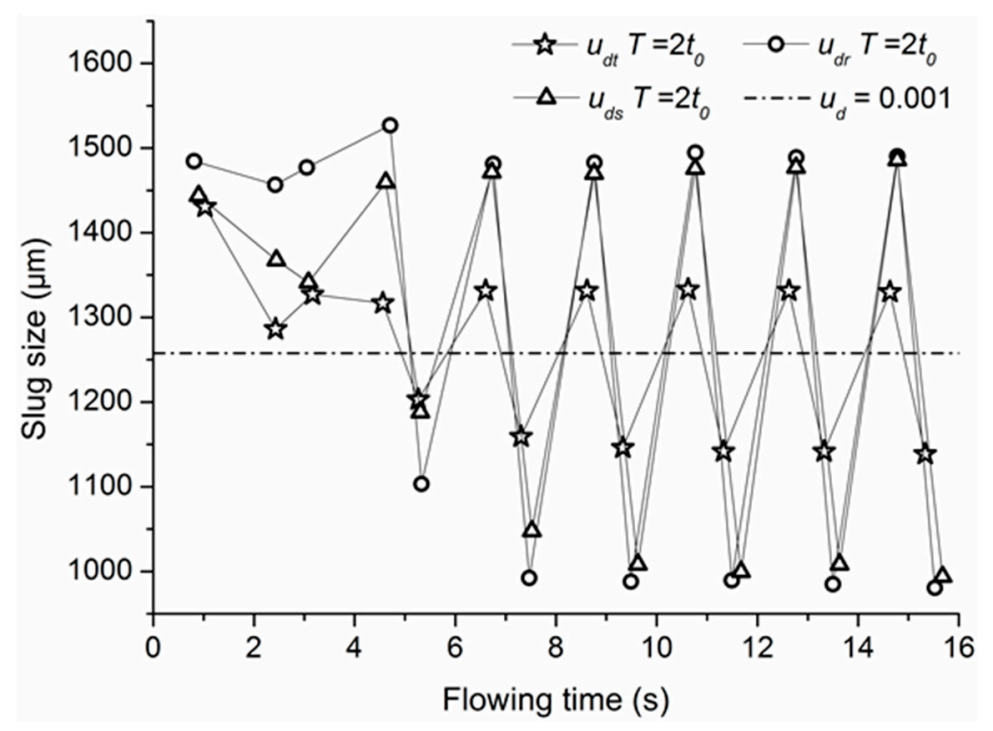

Figure 10. Slug size obtained from numerical simulations for dynamic dispersed injection flow rate of different types.

The separation distances for dynamic dispersed phase injection flow rates of different type are shown in Figure 11. For the three types of the dynamic dispersed injection flow rate, the separation distance changes periodically, and it oscillates near $1,812.05 \mu \mathrm{m}$, which is the separation distance of the constant injection flow rate. Concerning the amplitude of the separation distance, the sine wave dynamic dispersed phase injection flow rate has the minimum amplitude, which is about $230 \mu \mathrm{m}$, while the amplitude of the separation distance for the triangle wave dynamic dispersed phase injection flow rate is the maximum, which is about $569 \mu \mathrm{m}$.

Figure 12 presents the slug generation time for the different types of the dynamic dispersed phase injection flow rate. It is found that for these three types of the dynamic dispersed phase injection flow rate, the slug generation time changes periodically. When the dynamic dispersed phase injection flow rate is a sine wave, the amplitude of the slug generation time is the minimum, which is about $0.12 \mathrm{~s}$. However, when the dynamic dispersed phase injection flow rate is a triangle wave, the amplitude of the slug generation time is the maximum, which is about $0.30 \mathrm{~s}$. It is indicated that for the different types of the dynamic dispersed phase injection flow rate, the slug size, the separation distance and the slug generation time change periodically, and they oscillate near the values obtained under the condition of a constant injection flow rate. The types of the dynamic dispersed phase injection flow rate affect the vibration amplitude obviously. 


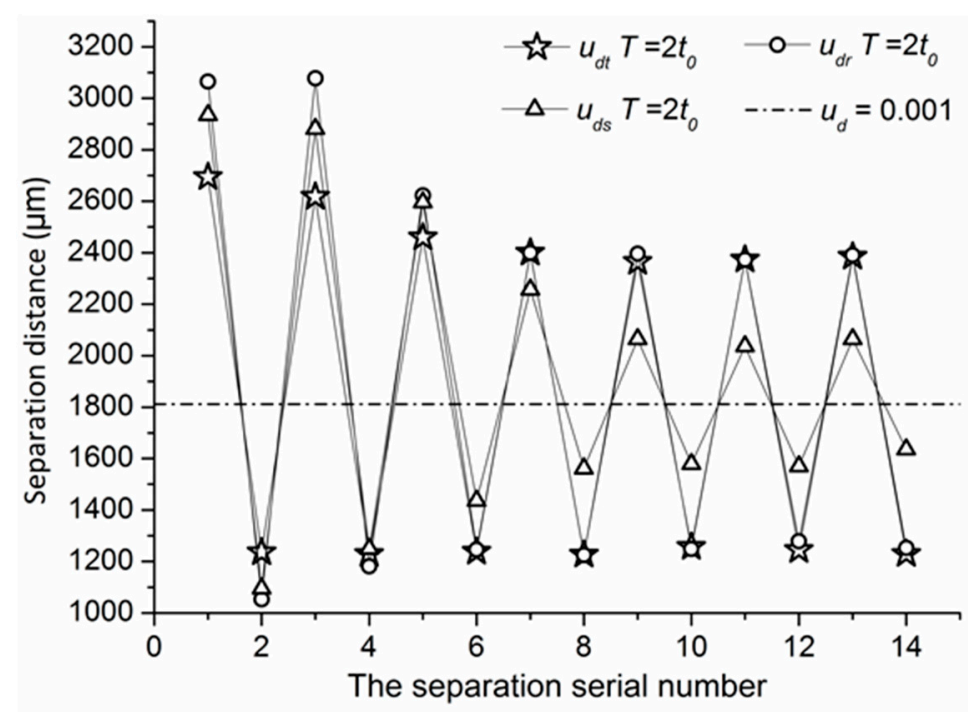

Figure 11. Separation distance obtained from numerical simulations for dynamic dispersed injection flow rate of different types.

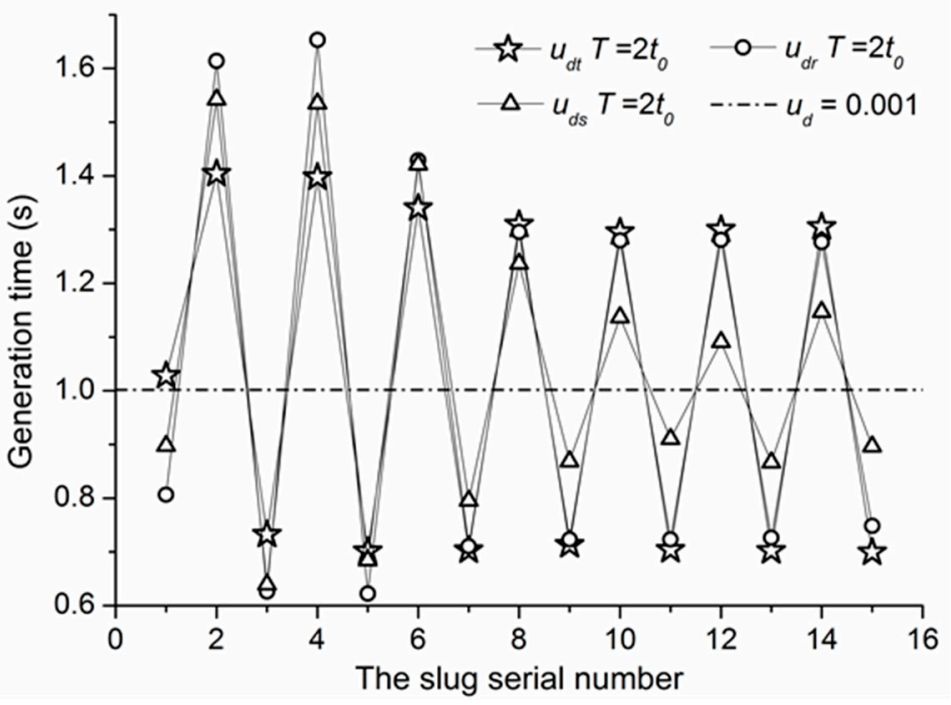

Figure 12. Slug generation time obtained from numerical simulations for dynamic dispersed injection flow rate of different types.

\section{Conclusions}

This work investigated the effects of a dynamic dispersed phase injection flow rate on the slug generation, in which the different cycles and different types of the dispersed phase injection flow rate were simulated numerically. The results show that the dynamic dispersed phase injection flow rate influences the slug generation observably. Especially when the cycle is larger than $t_{0}$, the slug generation changes periodically. For the same flux of the dispersed phase in one flow rate cycle, the sums of slug generation characteristics, including the slug size, the separation distance and the slug generation time, are equal, no matter whether the dispersed phase injection flow rate is constant or dynamic. Finally, for a fixed cycle, the dynamic dispersed phase injection flow rates with different types affect the oscillating amplitude of the slug size, separation distance and slug generation time obviously. Among these, the rectangular wave dynamic dispersed phase injection flow rate has the greatest influence on the slug size oscillation amplitude, while the triangle wave dispersed phase injection affects the separation distance and the slug generation time most significantly. 
Author Contributions: Data curation, J.-y.Q., M.-r.C. and Z.W.; Formal analysis, M.-r.C.; Funding acquisition, J.-y.Q.; Investigation, M.-r.C.; Methodology, Z.W.; Project administration, Z.-j.J. and B.S.; Resources, B.S.; Supervision, J.-y.Q., Z.-j.J. and B.S.; Writing-Original Draft, J.-y.Q. and M.-r.C.; Writing—Review \& Editing, B.S.

Funding: This research was funded by National Natural Science Foundation of China through, grant number 51,805,470; the Fundamental Research Funds for the Central Universities, grant number 2018QNA4013, and the Youth Funds of the State Key Laboratory of Fluid Power and Mechatronic Systems (Zhejiang University), grant number SKLoFP-QN-1801; the Fundamental Research Funds for the Central Universities, grant number 2018FZA213.

Conflicts of Interest: The authors declare no conflict of interest.

\section{References}

1. Maan, A.A.; Nazir, A.; Khan, M.K.I.; Boom, R.; Schroën, K. Microfluidic emulsification in food processing. J. Food Eng. 2015, 147, 1-7. [CrossRef]

2. Qian, J.; Li, X.; Wu, Z.; Bengt, S. A comprehensive review on liquid-liquid two-phase flow in microchannel: Flow pattern and mass transfer. Microfluid. Nanofluidics 2019, 23, 116. [CrossRef]

3. Kurimoto, R.; Nakazawa, K.; Minagawa, H.; Yasuda, T. Prediction models of void fraction and pressure drop for gas-liquid slug flow in microchannels. Exp. Therm. Fluid Sci. 2017, 88, 124-133. [CrossRef]

4. Liu, D.; Ling, X.; Peng, H. Experimental and numerical studies on microbubble generation and flow behavior in a microchannel with double flow junctions. Ind. Eng. Chem. Res. 2016, 55, 12276-12286. [CrossRef]

5. Patel, R.S.; Weibel, J.A.; Garimella, S.V. Characterization of liquid film thickness in slug-regime microchannel flows. Int. J. Heat Mass Transf. 2017, 115, 1137-1143. [CrossRef]

6. Rocha, L.A.M.; Miranda, J.M.; Campos, J.B.L.M. Wide range simulation study of taylor bubbles in circular milli and microchannels. Micromachines 2017, 8, 154. [CrossRef]

7. Kingston, T.A.; Weibel, J.A.; Garimella, S.V. An experimental method for controlled generation and characterization of microchannel slug flow boiling. Int. J. Heat Mass Transf. 2017, 106, 619-628. [CrossRef]

8. Svetlov, S.D.; Abiev, R.S. Formation mechanisms and lengths of the bubbles and liquid slugs in a coaxial-spherical micro mixer in Taylor flow regime. Chem. Eng. J. 2018, 354, 269-284. [CrossRef]

9. Yao, C.; Dong, Z.; Zhao, Y.; Chen, G. An online method to measure mass transfer of slug flow in a microchannel. Chem. Eng. Sci. 2014, 112, 15-24. [CrossRef]

10. Yao, C.; Dong, Z.; Zhao, Y.; Chen, G. The effect of system pressure on gas-liquid slug flow in a microchannel. AIChE J. 2014, 60, 1132-1142. [CrossRef]

11. Yao, C.; Liu, Y.; Zhao, S.; Dong, Z.; Chen, G. Bubble/droplet formation and mass transfer during gas-liquid-liquid segmented flow with soluble gas in a microchannel. AIChE J. 2017, 63, 1727-1739. [CrossRef]

12. Yin, Y.; Zhu, C.; Guo, R.; Fu, T.; Ma, Y. Gas-liquid two-phase flow in a square microchannel with chemical mass transfer: Flow pattern, void fraction and frictional pressure drop. Int. J. Heat Mass. Transf. 2018, 127, 484-496. [CrossRef]

13. Liu, Q.; Wang, W.; Palm, B. A numerical study of the transition from slug to annular flow in micro-channel convective boiling. Appl. Therm. Eng. 2017, 112, 73-81. [CrossRef]

14. Magnini, M.; Thome, J.R. A CFD study of the parameters influencing heat transfer in microchannel slug flow boiling. Int. J. Therm. Sci. 2016, 110, 119-136. [CrossRef]

15. Magnini, M.; Thome, J.R. An updated three-zone heat transfer model for slug flow boiling in microchannels. Int. J. Multiphase Flow 2017, 91, 296-314. [CrossRef]

16. Li, H.; Hrnjak, P. Flow visualization of R32 in parallel-port microchannel tube. Int. J. Heat Mass Transf. 2019, 128, 1-11. [CrossRef]

17. Garstecki, P.; Fuerstman, M.J.; Stonec, H.A.; Whitesides, G.M. Formation of droplets and bubbles in a microfluidic T-junction-Scaling and mechanism of break-up. Lab. Chip 2006, 6, 437-446. [CrossRef]

18. Sattari-Najafabadi, M.; Esfahany, M.N.; Wu, Z.; Sundén, B. Hydrodynamics and mass transfer in liquid-liquid non-circular microchannels: Comparison of two aspect ratios and three junction structures. Chem. Eng. J. 2017, 322, 328-338. [CrossRef]

19. Sattari-Najafabadi, M.; Nasr Esfahany, M.; Wu, Z.; Sundén, B. The effect of the size of square microchannels on hydrodynamics and mass transfer during liquid-liquid slug flow. AIChE J. 2017, 63, 5019-5028. [CrossRef] 
20. Kovalev, A.V.; Yagodnitsyna, A.A.; Bilsky, A.V. Flow hydrodynamics of immiscible liquids with low viscosity ratio in a rectangular microchannel with T-junction. Chem. Eng. J. 2018, 352, 120-132. [CrossRef]

21. Carneiro, J.; Campos, J.B.L.M.; Miranda, J.M. High viscosity polymeric fluid droplet formation in a flow focusing microfluidic device-Experimental and numerical study. Chem. Eng. Sci. 2019, 195, 442-454. [CrossRef]

22. Zhang, Q.; Zhu, C.; Du, W.; Liu, C.; Fu, T.; Ma, Y.; Li, H.Z. Formation dynamics of elastic droplets in a microfluidic T-junction. Chem. Eng. Res. Des. 2018, 139, 188-196. [CrossRef]

23. Qian, J.; Li, X.; Wu, Z.; Jin, Z.; Zhang, J.; Bengt, S. Slug formation analysis of liquid-liquid two-phase flow in T-junction microchannels. J. Therm. Sci. Eng. Appl. 2019, 11. [CrossRef]

24. Man, J.; Li, Z.; Li, J.; Chen, H. Phase inversion of slug flow on step surface to form high viscosity droplets in microchannel. Appl. Phys. Lett. 2017, 110, 181601. [CrossRef]

25. Wehking, J.D.; Gabany, M.; Chew, L.; Kumar, R. Effects of viscosity, interfacial tension, and flow geometry on droplet formation in a microfluidic T-junction. Microfluid. Nanofluid. 2014, 16, 441-453. [CrossRef]

26. Zhang, Q.; Liu, H.; Zhao, S.; Yao, C.; Chen, G. Hydrodynamics and mass transfer characteristics of liquid-liquid slug flow in microchannels: The effects of temperature, fluid properties and channel size. Chem. Eng. J. 2019, 358, 794-805. [CrossRef]

27. Song, Y.; Song, J.; Shang, M.; Xu, W.; Liu, S.; Wang, B.; Lu, Q.; Su, Y. Hydrodynamics and mass transfer performance during the chemical oxidative polymerization of aniline in microreactors. Chem. Eng. J. 2018, 353, 769-780. [CrossRef]

28. Qian, J.; Li, X.; Gao, Z.; Jin, Z. Mixing efficiency analysis on droplet formation process in microchannels by numerical methods. Processes 2019, 7, 33. [CrossRef]

29. Van Loo, S.; Stoukatch, S.; Kraft, M.; Gilet, T. Droplet formation by squeezing in a microfluidic cross-junction. Microfluid. Nanofluid. 2016, 20, 146. [CrossRef]

30. Zhao, W.; Zhang, S.; Lu, M.; Shen, S.; Yun, J.; Yao, K. Immiscible liquid-liquid slug flow characteristics in the generation of aqueous drops within a rectangular microchannel for preparation of poly(2hydroxyethylmethacrylate) cryogel beads. Chem. Eng. Res. Des. 2014, 92, 2182-2190. [CrossRef]

31. Malekzadeh, S.; Roohi, E. Investigation of different droplet formation regimes in a T-junction microchannel using the VOF technique in openfoam. Microgravity Sci. Technol. 2015, 27, 231-243. [CrossRef]

32. Gupta, A.; Sbragaglia, M. A lattice Boltzmann study of the effects of viscoelasticity on droplet formation in microfluidic cross-junctions. Eur. Phys. J. E 2016, 39, 1-15. [CrossRef] [PubMed]

33. Chen, X.; Glawdel, T.; Cui, N.; Ren, C.L. Model of droplet generation in flow focusing generators operating in the squeezing regime. Microfluid. Nanofluid. 2015, 18, 1341-1353. [CrossRef]

34. Li, X.B.; Li, F.C.; Yang, J.C.; Kinoshita, H.; Oishi, M.; Oshima, M. Study on the mechanism of droplet formation in T-junction microchannel. Chem. Eng. Sci. 2012, 69, 340-351. [CrossRef]

35. Ładosz, A.; von Rohr, P.R. Pressure drop of two-phase liquid-liquid slug flow in square microchannels. Chem. Eng. Sci. 2018, 191, 398-409. [CrossRef]

36. Qian, J.; Li, X.; Gao, Z.; Jin, Z. Mixing efficiency and pressure drop analysis of liquid-liquid two phases flow in serpentine microchannels. J. Flow Chem. 2019, 9, 187-197. [CrossRef]

37. Qian, J.; Chen, M.; Liu, X.; Jin, Z. A numerical investigation of the flow of nanofluids through a micro Tesla valve. J. Zhejiang Univ. Sci. A 2018, 20, 50-60. [CrossRef]

38. Cao, Z.; Wu, Z.; Sundén, B. Dimensionless analysis on liquid-liquid flow patterns and scaling law on slug hydrodynamics in cross-junction microchannels. Chem. Eng. J. 2018, 344, 604-615. [CrossRef]

39. Fletcher, D.F.; Haynes, B.S. CFD simulation of Taylor flow: Should the liquid film be captured or not? Chem. Eng. Sci. 2017, 167, 334-335. [CrossRef]

(C) 2019 by the authors. Licensee MDPI, Basel, Switzerland. This article is an open access article distributed under the terms and conditions of the Creative Commons Attribution (CC BY) license (http://creativecommons.org/licenses/by/4.0/). 